\title{
Estado da arte em agroecologia e suas relações com experiências no sul de Minas Gerais
}

\author{
State of the art in agroecology and its relationship \\ with experiences in southern Minas Gerais
}

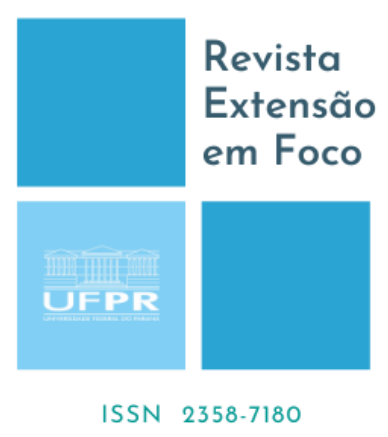

\section{João Barcellos Xavier ${ }^{1}$, Wilson Magela Gonçalves ${ }^{2}$, Thiago Rodrigo de Paula Assis ${ }^{3}$, Luciane Vilela Resende ${ }^{4}$, Douglas Correa de Souza ${ }^{5}$}

\begin{abstract}
RESUMO
O presente trabalho procurou identificar inovações tecnológicas no campo da agroecologia, com base em trabalhos científicos em nível mundial e as suas relações com as experiências agroecológicas do Sul de Minas Gerais. Foi realizada pesquisa bibliográfica e bibliométrica abrangendo estudos científicos sobre agroecologia e agricultura orgânica. Para isso, foi realizado uma busca nas bases de periódicos SciVerse Scopus, Web of Science e Scielo. Foi sistematizado o estado da arte em agroecologia. Ao mesmo tempo foi feita uma pesquisa ao nível de campo como um estudo de caso, caracterizando e mapeando as experiências regionais por meio de questionários semiestruturados. Após as coletas e análises dos dados provenientes do conhecimento científico e da prática das famílias agricultoras, foi possível realizar relações entre os dois conhecimentos. Foram contabilizados 4.739 registros de documentos científicos. Foram entrevistadas 10 organizações de agricultores. Foram identificadas técnicas e inovações em agroecologia, obtendo-se uma alta relação entre os conhecimentos científicos e a prática local dos agricultores agroecológicos do Sul de Minas Gerais.
\end{abstract}

Palavras-chave: Tecnologias ecológicas. Agricultura ecológica. Agricultura orgânica. Estudo bibliométrico.

\section{ABSTRACT}

The present work identifies technological innovations in the agroecological field based in global scientific papers and their relations with the agroecological experiences in the South of Minas Gerais. For this study was made a bibliografic and bibliometric research based on scientific studies in agroecology and organic agriculture. To achive the results, a research was made in the following periodic bases: SciVerse Scopus, Web of Science and Scielo. The state of art in agroecology was systematized. A research in the field level with a study of case were made. The regional experience was characterized and located by a semistructured questionnaire. After collecting and analyzing data provenient of scientific knowledge and practices used by family agricultures, it was possible to determine the relations between this different types of knowledge. It were contabilized 4,739 registres of scientific papers. The interviews were made with 10 organizations of smallholders farmers. Techniques and innovations in agroecology were

\footnotetext{
${ }^{1}$ Doutorado em Agronomia/Fitotecnia. Universidade Federal de Lavras (UFLA), Lavras, Minas Gerais, Brasil. E-mail: bxjoao@yahoo.com. Orcid: https://orcid.org/0000-0001-8058-7400

${ }^{2}$ Doutorado em Agronegócios. Universidade Federal do Rio Grande do Sul (UFRGS). Porto Alegre, Rio Grande do Sul, Brasil. E-mail: wilson_magela@hotmail.com. Orcid: http://orcid.org/0000-0001-6701$\underline{5037}$

${ }^{3}$ Doutorado em Ciências Sociais em Desenvolvimento, Agricultura e Sociedade. Universidade Federal Rural do Rio de Janeiro (UFRRJ), Seropédica, Rio de Janeiro, Brasil. E-mail: thiagoassis@dae.ufla.br. Orcid: https://orcid.org/0000-0002-5330-8856

${ }^{4}$ Doutorado em Agronomia/Fitotecnia. Universidade Federal de Lavras (UFLA), Lavras, Minas Gerais, Brasil. E-mail: lucianevilela@ dag.ufla.br. Orcid: https://orcid.org/0000-0002-2014-4453

${ }_{5}^{5}$ Doutorado em Agronomia/Fitotecnia. Universidade Federal de Lavras (UFLA), Lavras, Minas Gerais, Brasil. E-mail: douglascorrea@ymail.com. Orcid: https://orcid.org/0000-0003-3956-1342
} 
identified, yielding a high afinity between scientific knowledge and the local practices held by agroecological farmers in southern Minas Gerais.

Keywords: Ecological Technologies. Ecological agriculture. Organic agriculture. Bibliometric study.

\section{INTRODUÇÃO}

A agroecologia é uma ciência multidisciplinar, que abrange diversas ciências e conhecimentos, incentivando uma forma mais holística de agricultura. Seus princípios são baseados nos valores econômicos, ecológicos, sociais, culturais, políticos e éticos, levando-se em conta suas diversas interações, relacionando-as com a agricultura e a sociedade. A agroecologia procura valorizar o conhecimento tradicional dos agricultores e sua participação para construção de uma ciência que seja mais acessível e justa com as pessoas que dela necessitam, buscando técnicas que consistam em ser realmente sustentáveis de acordo com os seus princípios metodológicos.

Este conhecimento tem crescido no mundo inteiro, sendo implantado em diversas instituições de pesquisa, ensino, extensão e associações/grupos de agricultores.

A agroecologia e a agricultura orgânica apesar de possuírem conceitos semelhantes são definições totalmente diferentes. A agroecologia é uma ciência que possuí diversos princípios, uma filosofia e metodologias específicas, em busca de um novo enfoque científico. Por outro lado, o conceito da agricultura orgânica emerge em um contexto mais prático e técnico, sem realizar grandes reflexões quanto às questões socioeconômicas da sociedade.

Inovação tecnológica é a introdução de uma novidade dentro de um determinado ramo ou conhecimento, que ocasione no avanço tecnológico de sua área pertencente. Portanto, a mensuração e a identificação de inovações tecnológicas no campo da agroecologia podem proporcionar diversos benefícios a esta ciência.

Para se realizar a mensuração de inovações, sugere-se o uso de indicadores de inovação tecnológica para auxiliar na análise dos avanços tecnológicos da agroecologia. Esses indicadores permitem medir os seus índices de investimento, os resultados gerados, suas relações em tempo real e em escala global.

As publicações científicas são indicadores de inovação tecnológica, sendo este um indicador de produto que representa o resultado do esforço de pessoas envolvidas e de recursos aplicados na produção do conhecimento. 
Por outro lado, torna-se importante estabelecer relações entre essas tecnologias e as experiências agroecológicas locais, para que se tenha o conhecimento da prática realizada em campo, identificando pontos chave de inovação para o seu progresso. As relações entre os conhecimentos científico e prático permitem uma maior compreensão do estado da arte da agroecologia e da agricultura orgânica, podendo avaliar se a ciência e a prática dos agricultores locais são compatíveis e se suas demandas são alvo de estudos científicos.

A sistematização do conhecimento agroecológico deve ser ampliada, necessitando de estudos científicos que corroborem o potencial desta ciência e o saber dos agricultores possuindo como princípios melhorar as relações de trabalho, renda e mercado; recuperar e preservar recursos naturais e a biodiversidade (agrícola e ambiental); melhorar a qualidade de vida da população rural e urbana de forma a garantir os seus direitos básicos; respeitar e valorizar os costumes culturais tradicionais; realizar a participação política e a organização da população de forma participativa independentemente de sua classe social ou raça; respeitar os valores éticos e as demandas da sociedade (EMBRAPA, 2006).

No presente trabalho, o objetivo foi identificar inovações tecnológicas no campo da agroecologia com base em trabalhos científicos em nível mundial e verificar suas relações com as experiências agroecológicas do Sul de Minas Gerais, tornando possível verificar o estado da arte em agroecologia e agricultura orgânica e caracterizar as experiências agroecológicas do Sul de Minas Gerais.

\section{MATERIAIS E MÉTODOS}

Para alcançar os objetivos deste trabalho foram realizadas uma pesquisa bibliográfica, bibliométrica e uma pesquisa de campo por meio de um estudo de caso. A partir destas pesquisas foi possível relacionar as informações contidas nos trabalhos científicos em nível mundial com as experiências locais dos agricultores.

\section{Pesquisa bibliográfica e bibliométrica}

Os dados desta seção foram obtidos no portal de periódicos da Coordenação de Aperfeiçoamento de Pessoal de Nível Superior (CAPES), que apresenta de forma gratuita às universidades brasileiras diversas bases de referencial multidisciplinar de 
dados, onde foram pesquisados os dados relacionados à agroecologia e à agricultura orgânica. Realizou-se uma busca nas bases de periódicos SciVerse Scopus, Web of Science (interligado à base do Institute for Scientific Information) e Scielo (Scientific Eletronic Library Online), que representam um acervo de milhares de periódicos (em torno de 27 mil), contendo artigos e patentes de relevância científica em escala global. Estas bases são reconhecidas por sua tradição e amplitude nos estudos bibliométricos, informando a qualidade e a visibilidade das publicações científicas de determinadas áreas do conhecimento (SOUZA et al., 2013).

O presente estudo possui um caráter exploratório, levando-se em conta, que este é um primeiro contato com o tema, com o propósito de conhecer o avanço da agroecologia no mundo científico. Portanto, não foi formulada uma proposição teórica a ser testada, mas sim, buscaram-se o entendimento, as direções e as características da produção científica da área (SANTOS; PISCOPO, 2013).

Para explorar este universo científico, esta pesquisa baseou-se em duas palavraschave para a busca ao acervo nas bases de periódicos citadas anteriormente. Utilizou-se como filtro as palavras-chave: agroecologia e agricultura orgânica ambas no idioma inglês (agroecology e organic agriculture).

Todos os anos que tiveram documentos registrados de 1958 até o dia 31 de dezembro de 2013 foram analisados. Neste estudo foram utilizados os indicadores de inovação tecnológica de segunda geração, que são utilizados como uma ferramenta para medir os resultados e produtos provenientes da inovação, como as publicações científicas, patentes, fatores de impacto, a qualidade de revistas e publicações, entre outros.

Entre as referências registradas, foram removidas as referências duplicadas que estavam superestimando o valor real dos registros nas bases de periódicos. Foram totalizadas 3.306 referências de artigos identificados pelas palavras-chave "Agroecology" e "Organic Agriculture". Foram selecionados 1.175 artigos (35,5\% do total) de forma aleatória, ou seja, não houve um critério de escolha considerando os autores, os títulos, as revista etc, e estratificada pelos anos de progressão da ciência, abrangendo desde os primeiros anos de registro de documentos até o ano de 2013. 
Foram lidos títulos e resumos dos artigos, com o propósito de verificar os temas e o que tem sido produzido por estas ciências. Posteriormente os artigos foram divididos em categorias (político, social, econômico, ambiental, saúde, conceitos gerais de agroecologia, conhecimento técnico produtivo, outros, não é agroecologia, artigos com resumos não encontrados) e subcategorias de acordo com as informações proporcionadas. Os resumos de artigos relacionados com o conhecimento técnico produtivo tiveram os seus objetivos e conclusões selecionados para auxiliar na relação do conhecimento científico global com a prática local do Sul de Minas Gerais.

\section{Pesquisa de campo}

Em resumo, a pesquisa de campo foi dividida em duas etapas:

I. Entrevistas foram feitos (por meio de um questionário semiestruturado) com entidades, organizações, órgãos públicos e pessoas envolvidas com agroecologia no Sul de Minas, estas entidades foram as "informantes" sobre as experiências agroecológicas locais. Como resultado destas entrevistas tornou-se possível a identificação e a localização das comunidades rurais, associações ou grupos de agricultores que trabalham com agroecologia ou agricultura orgânica.

II. Foram selecionadas para a pesquisa as experiências que possuíam um caráter mais organizado e que contemplassem grupos de agricultores. Posteriormente, foram efetuadas visitas e entrevistas com questionário semiestruturado às organizações de agricultores (totalizando-se 10). Estas entrevistas tiveram como foco conhecer as formas de produção das famílias agricultoras, o manejo da terra, o controle de pragas e doenças, a utilização de insumos, sua forma de organização entre outros temas. Em seguida, foram realizadas visitas às propriedades chave destas organizações com o propósito de conhecer a prática e o saber destes agricultores por meio de caminhadas participativas.

Foram entrevistados agricultores das seguintes organizações: Serras Altas da Mantiqueira, Associação Permacultural Montanhas da Mantiqueira (APOMM), Ecominas, Assentamento Santo Dias, Associação de Produtores de Agricultura Natural de Maria da Fé (APANFÉ), Associação de Bananicultores de Luminosa (ABAL), 
Associação de Agricultura Orgânica e Biodinâmica Serras Verdes, Orgânicos da Mantiqueira, Serras de Santana e Associação Agroecológica de Ouro Fino (AAOF).

\section{Relações entre o conhecimento científico e o conhecimento prático dos agricultores}

Após as coletas e análises dos dados provenientes do conhecimento científico mundial e da prática das famílias agricultoras locais, foi possível realizar relações entre os dois conhecimentos.

A categoria escolhida para relacionar as duas formas de conhecimento foi o conhecimento técnico produtivo. Foram criados quadros comparativos sobre as seguintes subcategorias: adubação orgânica; biofertilizantes e caldas; sistema de plantio; mecanização, tração e trabalho manual; técnicas e insumos biodinâmicos; consórcios agrícolas; controle biológico e uso de microrganismos; teoria da trofobiose; invenção e conhecimento tradicional; sementes e mudas.

As relações basearam-se em uma comparação entre os temas abordados pelos artigos em cada subcategoria mencionada e as práticas produtivas utilizadas pelos agricultores entrevistados. Portanto, se os agricultores e os artigos científicos citaram técnicas ou princípios iguais/semelhantes na mesma subcategoria, considerou-se que os conhecimentos possuíam uma alta relação naquele assunto. Caso contrário, se houve uma carência científica de determinadas técnicas ou uma falta de consistência entre os dois conhecimentos, eles têm uma baixa relação naquela subcategoria determinada.

Também foram estabelecidos critérios para quantificar o nível geral de relação entre o conhecimento científico e o prático. Como são 10 subcategorias tratadas, verificou-se a relação entre os dois conhecimentos por meio da soma das relações das subcategorias. A partir desta soma é verificado o nível de relação entre os conhecimentos de acordo com a regra proposta por este trabalho. Se a soma das altas relações for menor do que $40 \%$ as duas formas de conhecimento possuem uma baixa relação. Se a soma for entre $50 \%$ e $60 \%$ as duas formas de conhecimento possuem uma relação média. Se a soma for maior do que $70 \%$ as duas formas de conhecimento possuem uma alta relação.

\section{RESULTADOS E DISCUSSÃO}




\section{Aspectos gerais do estado da arte da agroecologia}

A partir da pesquisa realizada nas bases de periódicos, foi possível contabilizar a quantidade de documentos registrados com as palavras-chave "Agroecology" e “Organic Agriculture", representados na Tabela 1. A diferença de documentos entre as bases de periódicos é compreensível, pois cada base possui uma determinada quantidade dos mesmos, fazendo com que deste modo, as bases tenham números diferenciados de documentos publicados em relação à palavra-chave, podendo ocasionar também em sobreposições de periódicos e artigos entre as bases.

Conforme os dados, o termo agricultura orgânica tem se apresentado de forma mais representativa em relação à agroecologia quanto às publicações científicas, contendo um número superior de registros nas bases de periódicos. Esta representatividade da agricultura orgânica provavelmente está ligada à constante utilização do termo, que tem sido empregado na formulação de leis, programas governamentais, nos processos de certificações, além de estar intrínseco nas lógicas de mercado.

Tabela 1 - Base de periódico e a sua relação com o número de documentos registrados de acordo com a palavra-chave utilizada

\begin{tabular}{|c|c|c|c|}
\hline Base de periódicos & Período analisado & Palavra-chave & $\begin{array}{c}\text { Número de } \\
\text { documentos } \\
\text { registrados }\end{array}$ \\
\hline Web of Science & 1979 а 2013 & Agroecology & 473 \\
\hline SciVerse Scopus & 1985 a 2013 & Agroecology & 1.367 \\
\hline Scielo & 2003 a 2013 & Agroecology & 42 \\
\hline \multicolumn{3}{|c|}{ Subtotal Agroecology } & 1.882 \\
\hline Web of Science & 1979 a 2013 & Organic Agriculture & 1.214 \\
\hline SciVerse Scopus & 1985 a 2013 & Organic Agriculture & 1.593 \\
\hline Scielo & 2001 a 2013 & Organic Agriculture & 50 \\
\hline \multicolumn{3}{|c|}{ Subtotal Organic Agriculture } & 2.857 \\
\hline \multicolumn{3}{|c|}{ Total de documento registrados nas bases de periódicos } & 4.739 \\
\hline \multicolumn{3}{|c|}{$\begin{array}{l}\text { Total de documento registrados nas bases de periódicos sem } \\
\text { referencias duplicadas }\end{array}$} & 3.306 \\
\hline
\end{tabular}

Segundo os dados da tabela, é possível perceber que o lançamento dos documentos ligados à agricultura orgânica são anteriores aos da agroecologia, evidenciando assim, que o termo agricultura orgânica é precursor no mundo científico entre as temáticas. 
Contabilizados todos os registros nas diferentes bases de periódicos, foi possível realizar uma comparação entre as duas palavras-chave "Organic Agriculture" e "Agroecology". De acordo com a Figura 1, o ano de maior registro de documentos para a agricultura orgânica foi o de 2011, com 387 registros. Para a agroecologia o ano de 2011 também foi o mais produtivo, com 296 documentos. É possível perceber uma certa semelhança no progresso das publicações das duas áreas, fator interessante que releva a importância das duas temáticas e as suas evoluções no mundo científico.

Figura 1 - Número de documentos registrados por ano para as palavras-chaves "Organic Agriculture" e "Agroecology".

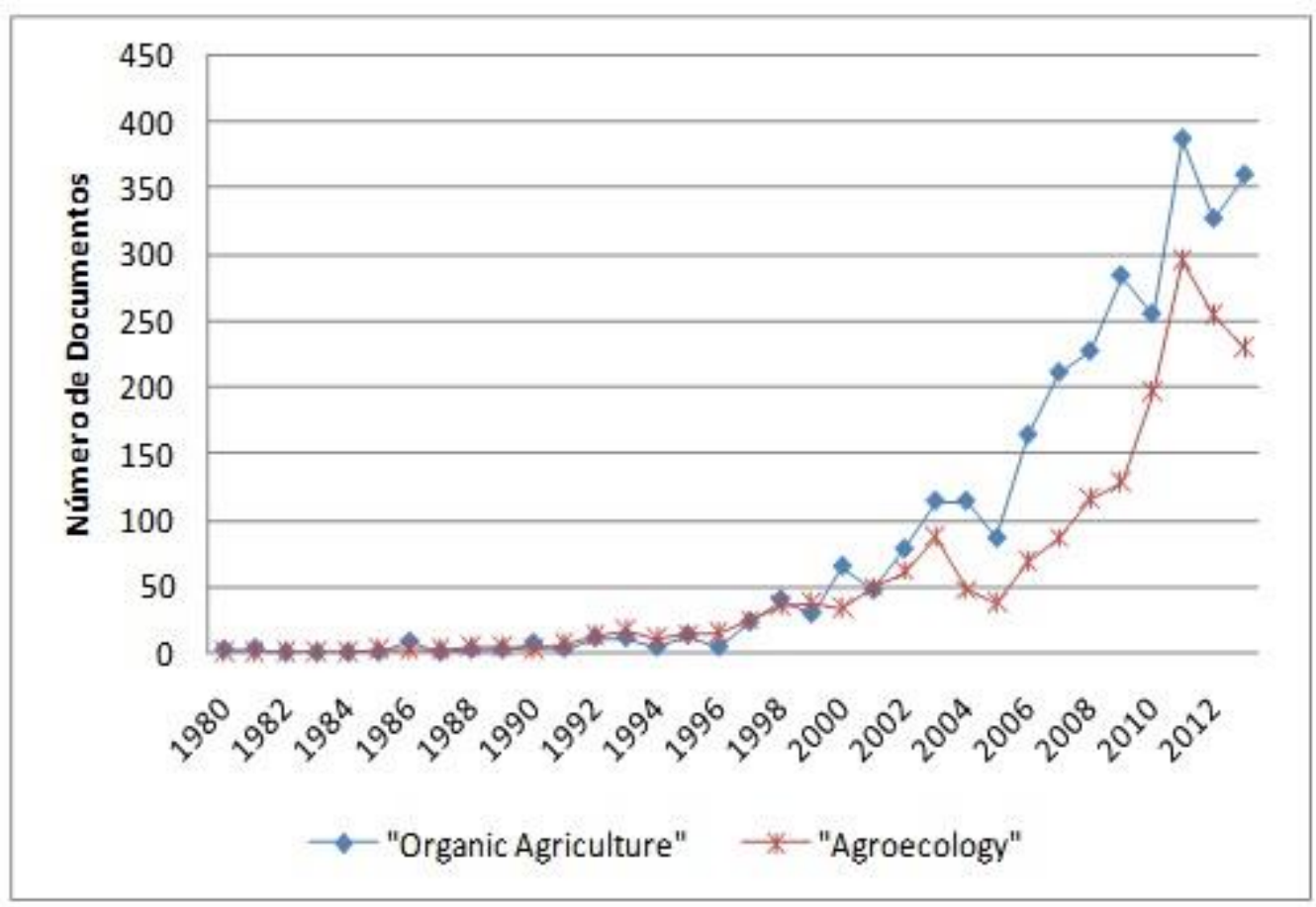

Fonte: Dados obtidos do Scielo (2014), SciVerse Scopus (2014) e Web of Science (2014).

Os 10 países que produziram mais documentos estão representados na Figura 2. Os dois países que mais publicaram foram os EUA e a China que, aparecem como os principais produtores de ciência em relação à agroecologia, registrando 311 e 256 documentos respectivamente. Vale ressaltar que o Brasil se encontra em terceiro lugar na produção destes documentos, com 102 registros.

Conforme os dados verifica-se uma abrangência territorial da produção científica da agroecologia, tendo, entre os 10 países que mais produzem documentos, distintas origens continentais, comprovando uma abrangência mundial das pesquisas relacionadas à agroecologia. 
Observa-se que os primeiros registros realizados pelo Brasil, em 2002, foram tardios, se comparados com outras partes do mundo. Mesmo assim, com o passar dos anos, há um notável crescimento das publicações nacionais que atingiram o seu ponto máximo em 2011, com 21 documentos (Figura 3).

Foram investigadas as dez instituições brasileiras que, nos últimos anos, mais produziram documentos relacionados à agroecologia (Figura 4). Observa-se a presença de diversas universidades federais e estaduais, e a Empresa Brasileira de Pesquisa Agropecuária (EMBRAPA) aparece como a principal produtora de documentos científicos sobre agroecologia.

Figura 2 - Número de documentos em relação ao país de origem

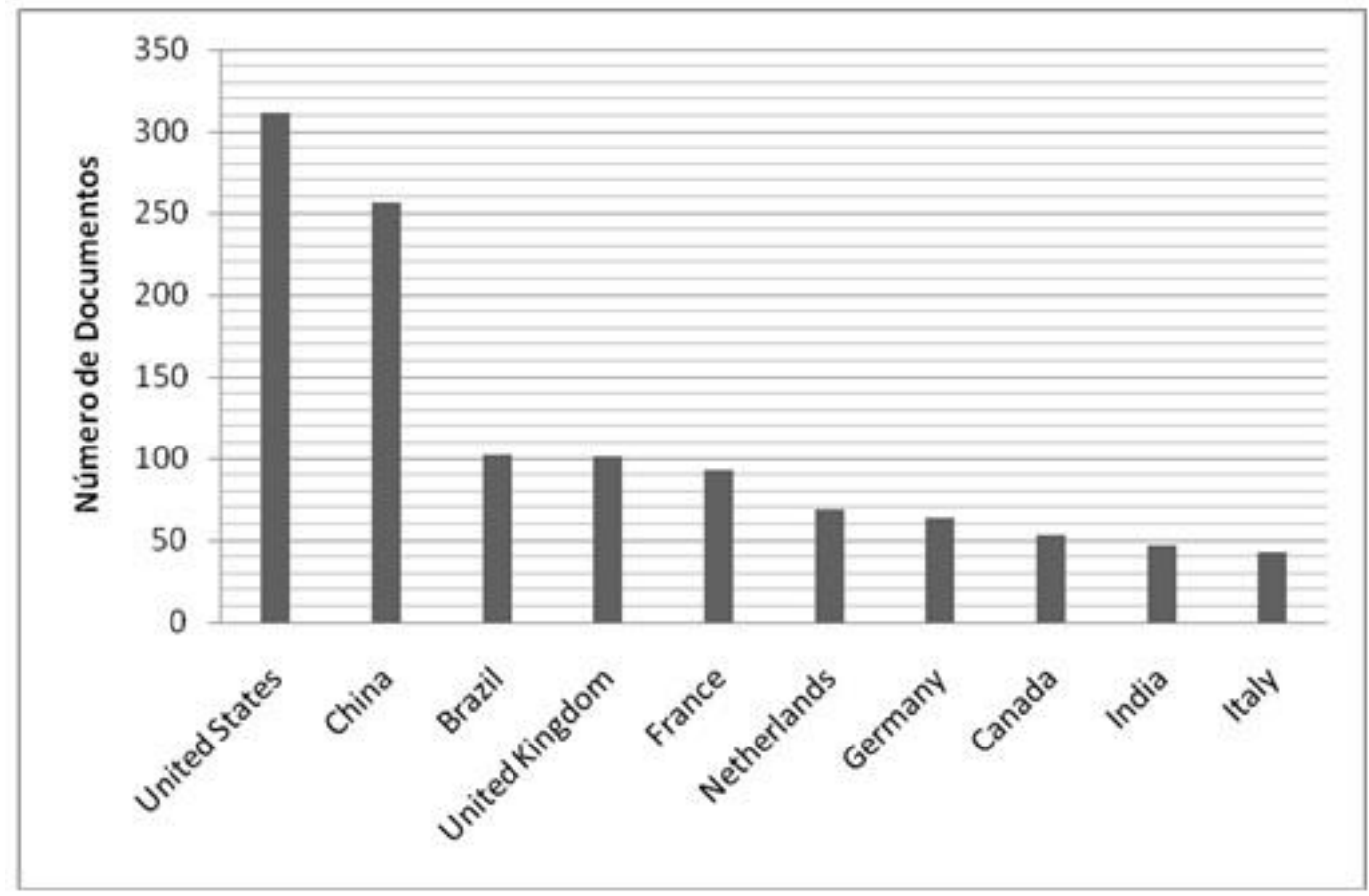

Fonte: Dados obtido do SciVerse Scopus (2014).

Figura 3 - Número de documentos registrados por ano no Brasil, com a palavra-chave "Agroecology". 


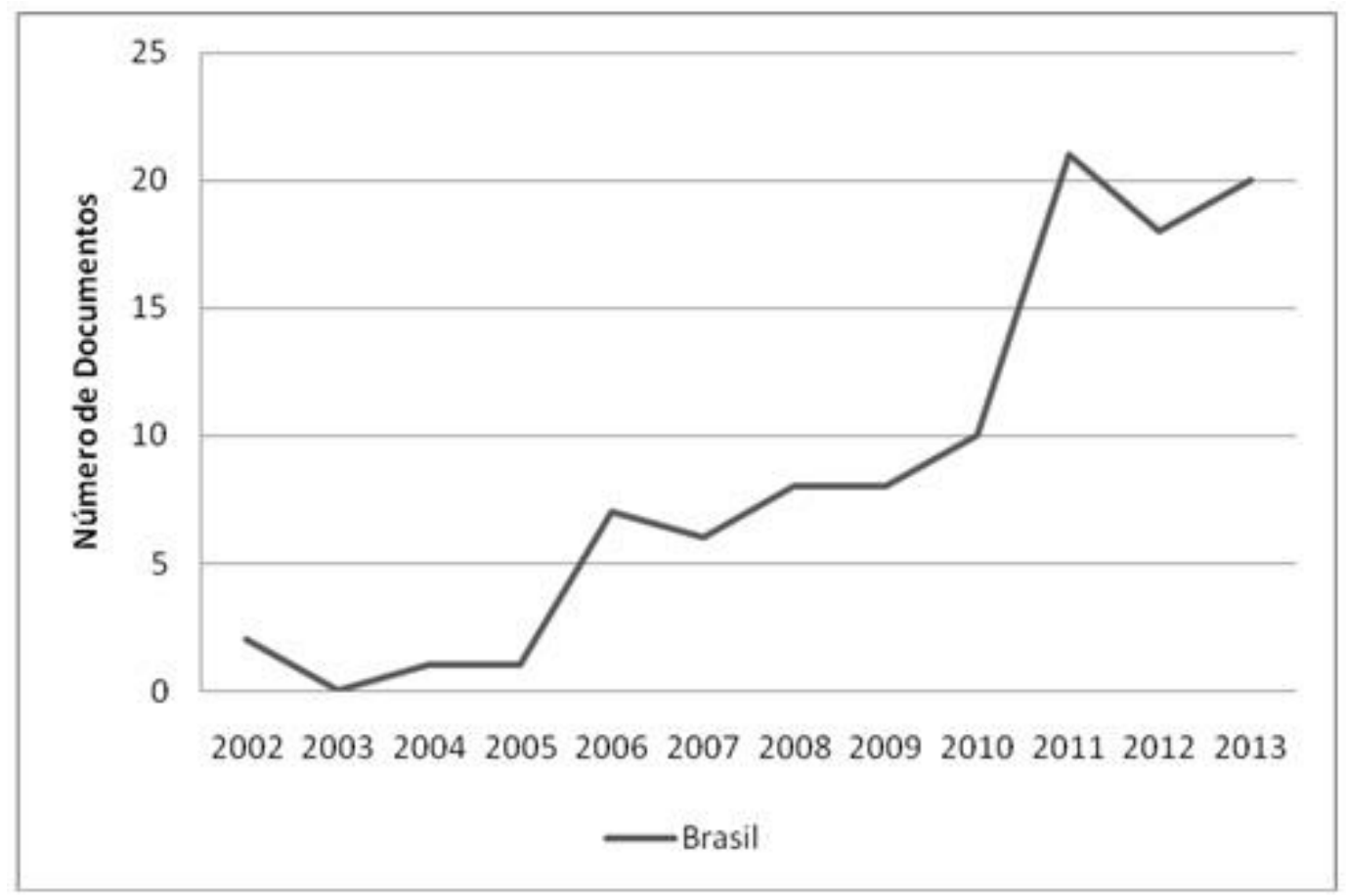

Fonte: Dados obtido do SciVerse Scopus (2014).

Figura 4 - Número de documentos registrados por instituições brasileiras.

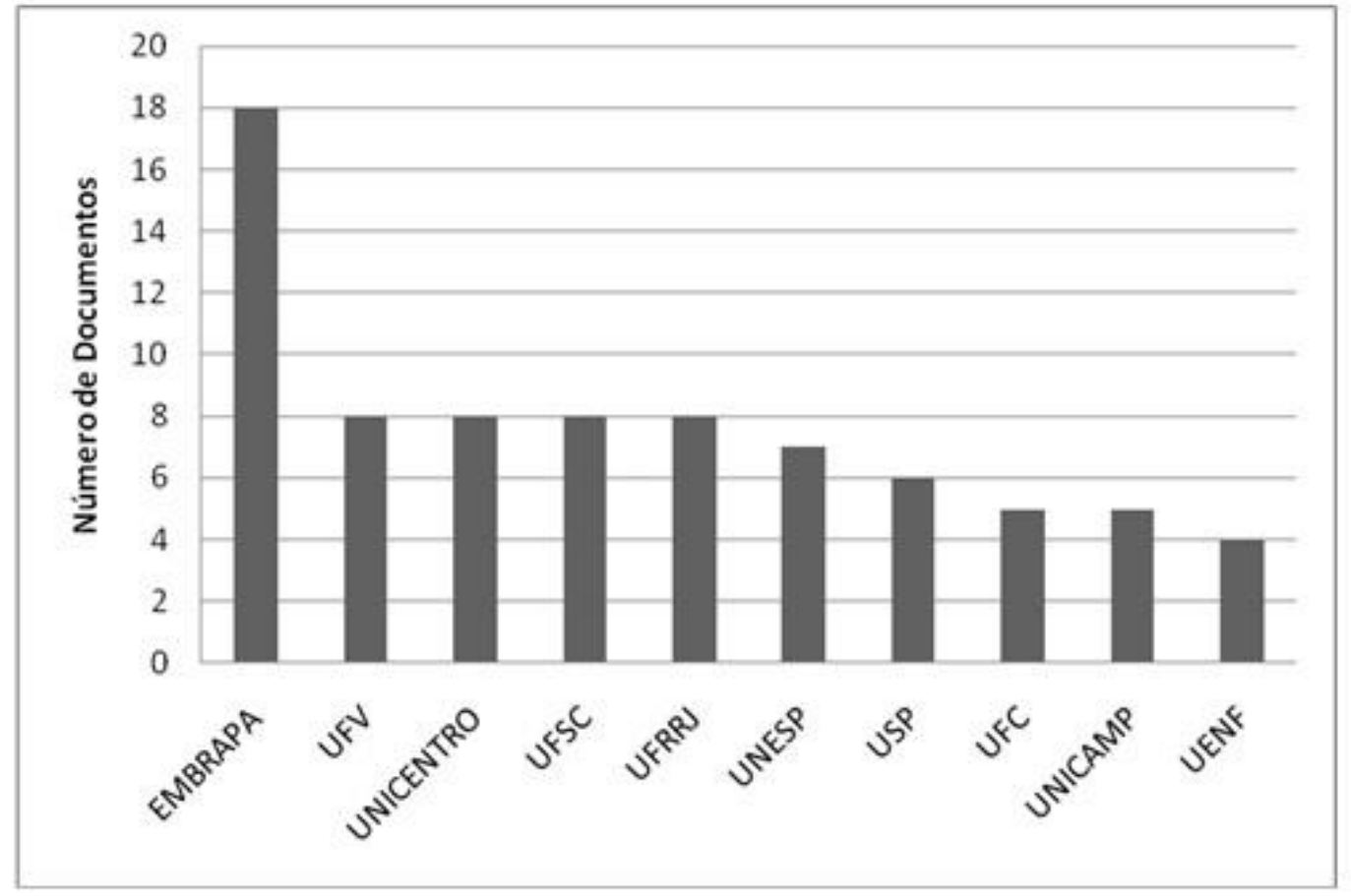

Fonte: Dados obtido do SciVerse Scopus (2014).

Refinamento dos artigos relacionados aos estudos científicos mundiais e nacionais sobre agroecologia e agricultura orgânica 
A partir da leitura dos títulos e resumos dos 1.175 artigos selecionados para o refinamento foi possível perceber que grande parte destes artigos versam principalmente sobre questões técnicas, ambientais e de conceituação desta ciência (Figura 5). Porém, há estudos nas áreas da economia, política, saúde e nas questões sociais. Entre os artigos selecionados, $3 \%$ não estão atrelados ao conceito da agroecologia, portanto, estes artigos foram retirados da análise. Contudo, $8 \%$ dos 1.175 artigos selecionados para o refinamento não tiveram os seus resumos encontrados, devido à existência de direitos autorais das revistas sobre as publicações dos artigos.

$\mathrm{Na}$ categoria "política" os temas mais comentados entre os artigos foram em relação às políticas públicas e programas governamentais existentes nos países, demonstrando diversas experiências pelo mundo. Relatos sobre desenvolvimento rural e como funcionam os sistemas agroalimentares nas distintas regiões foram feitos.

Os movimentos sociais e agroecológicos também foram tema dos artigos. Alguns tratam das dificuldades encontradas pelo campesinato e pelos povos indígenas (CARRUTHERS, 1997), como os conflitos rurais e as políticas muitas vezes excludentes deste público, existindo, em alguns casos guerras civis, como no caso da Colômbia (BRITTAIN; SACOUMAN, 2008).

Figura 5 - Divisão dos artigos selecionados por categoria 


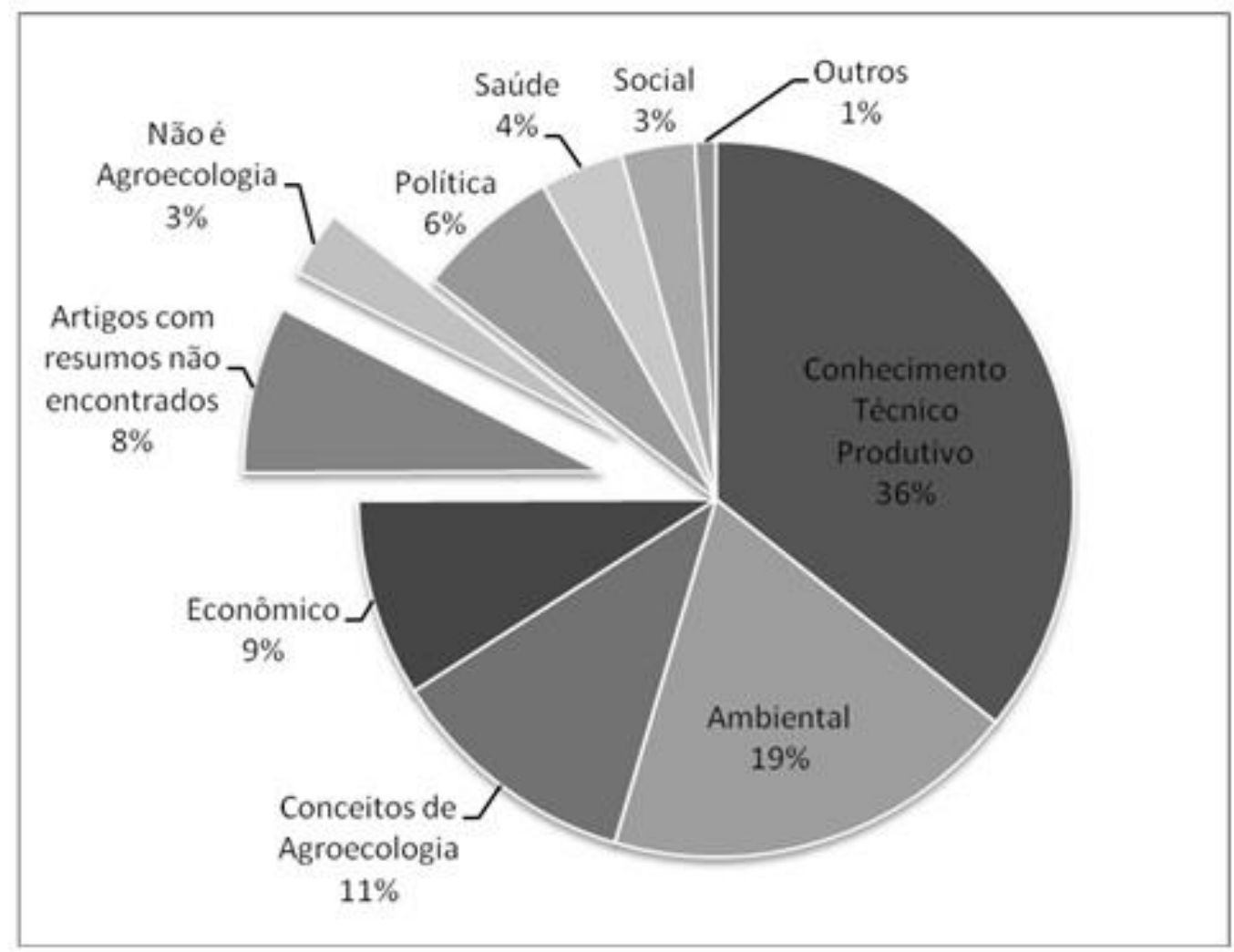

Fonte: Dados obtidos do Scielo (2014), SciVerse Scopus (2014) e Web of Science (2014).

Porém, outros trabalhos relatam experiências que superaram estas dificuldades e têm proporcionado uma revolução agroecológica no meio rural, criando inovações e mudanças dirigidas à autossuficiência local com a conservação dos recursos naturais, a produção de alimentos saudáveis e a capacitação de camponeses (ALTIERI; TOLEDO, 2011).

A organização de agricultores e associações também foi tema dos artigos presentes nesta categoria.

$\mathrm{Na}$ categoria "social", os artigos analisados apresentam informações principalmente sobre a segurança alimentar. Mostram distintas formas a importância da agricultura familiar para este tema, incentivando a revitalização destas famílias e suas propriedades, a integração e a participação das comunidades, e a valorização dos seus trabalhos. Estudos de caso em Cuba, Brasil, Filipinas e em países da África demonstram que esta é uma opção viável para garantir as necessidades alimentares presentes e futuras (ALTIERI; FUNES-MONZOTE; PETERSEN, 2012).

Outro tema abordado nesta categoria foi o do conhecimento tradicional e os costumes das famílias agricultoras, expondo a importância do conhecimento destes 
agricultores para a construção da agroecologia. A consolidação do conhecimento científico com o prático dos agricultores pode resultar na geração de um conhecimento que seja mais amplo e profundo ao mesmo tempo (VANDERMEER; PERFECTO, 2013).

No conjunto da categoria "social" também foram abordados temas como gênero, ética, cultura, etnia, êxodo rural e territorialidade.

Os trabalhos relacionados com a categoria "economia" retratam principalmente as questões de mercado, apontando que atualmente existem diversas possibilidades e oportunidades no mercado de produtos orgânicos e agroecológicos. Porém, um autor alerta sobre a "convencionalização" da agricultura orgânica, demonstrando que as forças de mercado têm incentivado um processo de industrialização desta agricultura, transformando-a numa agricultura de larga escala, contradizendo os princípios da autêntica agricultura orgânica e dos movimentos sociais que buscavam um sistema de cultivo mais equilibrado e baseado nas pequenas propriedades (CAMPBELL; ROSIN, 2011).

Os resumos dos artigos apresentam um pouco da evolução do conhecimento do consumidor em relação a esta forma de agricultura. A população se mostra cada vez mais atenta às questões do meio-ambiente e da saúde.

A certificação de produtos orgânicos e de agricultores também foi bastante citada entre os artigos desta categoria. Uma discussão interessante é a questão de como os agricultores de baixa renda são excluídos por este processo devido a questões financeiras. Existem muitos agricultores que comercializam produtos orgânicos, porém, não conseguem ter acesso à certificação, como é o caso de alguns agricultores da Argentina (CÁCERES, 2005).

Entretanto, existem experiências com processos de certificação participativa que buscam colaborar com os agricultores de baixa renda neste procedimento. Como é o exemplo das organizações entrevistados por esta pesquisa, que simbolizam um avanço quanto a esta questão. 
Essas organizações construíram em conjunto com parceiros o primeiro Organismo Participativo de Avaliação da Conformidade (OPAC) de Minas Gerais, a OPAC "Orgânicos Sul de Minas".

Trata-se de uma central de Associações que tem, entre outros objetivos, promover a certificação participativa e a aproximação entre as experiências da região.

Outros temas abordados pelos artigos relacionados à categoria "economia" foram: análises econômicas e questões em relação à pesquisa e desenvolvimento (P\&D) e inovação tecnológica.

A categoria "conceitos de agroecologia" proveu conhecimento científico principalmente na área da multidisciplinaridade, no conhecimento participativo e em relação à educação. Os trabalhos informam de modo geral a importância de o conhecimento funcionar de forma holística e participativa, ou seja, com a união de diversas ciências e saberes que contribuam para uma leitura mais ética da realidade.

Outros artigos fazem análises agroecológicas de sistemas de produção um exemplo desta forma de analisar os agroecossistemas é a crítica feita por Rosset e Altieri (1997) às agriculturas alternativas que em alguns momentos incentivam apenas as trocas dos insumos convencionais por insumos orgânicos, sem romper com a estrutura da monocultura e do modelo predominante de se fazer agricultura. Portanto, os autores concluem que, desta forma, as agriculturas sustentáveis diminuem muito o seu potencial em solucionar problemas sociais, econômicos e ambientais.

O progresso da agroecologia e da agricultura orgânica tem se mostrado promissor, diversos estudos têm relatado um crescimento acelerado da comercialização, produção e aceitação dos produtos orgânicos. Segundo estudos de Paull e Hennig (2011), ao realizar um mapeamento da agricultura orgânica no mundo, 37,2 milhões de hectares já são destinados a este sistema de produção (orgânicos ou em processo de conversão), estando distribuídos em cerca de 160 países. Um exemplo de crescimento deste setor é o México, onde os fatores sociais, ambientais, econômicos, culturais e políticos têm incentivado o desenvolvimento da agricultura orgânica como uma alternativa aos impactos negativos atribuídos à agricultura convencional. As estatísticas oficiais registram uma taxa de crescimento deste setor superior a 25\% no México (GÓMEZ CRUZ et al., 2010). 
Temas ligados aos princípios da agroecologia e estudos de revisão ou bibliométricos também foram relatados na categoria de "conceitos de agroecologia".

Estudos relacionados à categoria "saúde" apresentaram temas principalmente sobre os benefícios de uma alimentação saudável, correlacionando-a aos produtos provenientes das agriculturas ecológicas.

Existem diversas controvérsias sobre este tema, como: a sua repercussão sobre a saúde do ser humano, a qualidade dos alimentos orgânicos em comparação aos convencionais e a questão do preço daqueles produtos diferenciados. Apesar dos alimentos orgânicos se diferenciarem pela sua baixa toxicidade, maior tempo de prateleira e o maior teor de nutrientes em alguns alimentos, são necessários maiores estudos para dissolver estas controvérsias (SOUSA et al., 2012).

São confeccionados também debates sobre o uso dos agrotóxicos e os seus riscos à saúde. Os demais trabalhos discutem as relações entre o sistema de saúde e o uso destes alimentos, entre outros assuntos.

Em relação às questões presentes na categoria "ambiental", dos diversos tópicos apresentados o principal foco foram os problemas ambientais distribuídos por todo o mundo e a inquietação por parte da comunidade científica quanto à crise ambiental na qual vivemos.

A biodiversidade foi um dos temas mais debatidos, apresentando a sua importância para o meio ambiente e como a sociedade vem perdendo este fundamental recurso que viabiliza diversos serviços ambientais. Estudos de Perfecto e Vandermeer (2008) apresentam a importância da agricultura familiar com base nos princípios agroecológicos para criação de sistemas de produção mais equilibrados, que conservem a agrobiodiversidade. Os autores concluem que estes sistemas baseados em pequenas propriedades possuem uma matriz ecológica de maior qualidade, sendo importantíssima para uma agricultura de base mais sustentável.

Diversos artigos propõem análises de sustentabilidade, porém, sem serem baseadas especificamente nos princípios da agroecologia. 
Outros assuntos tratados pelos artigos foram: mudanças climáticas, viabilidade energética de sistemas agrícolas, biocombustíveis/energias renováveis, sequestro de carbono e recuperação ambiental.

A categoria mais citada entre os artigos selecionados sobre agroecologia e agricultura orgânica foi a do "conhecimento técnico produtivo", dividida em 14 subcategorias (adubação orgânica, sistemas de plantio, controle biológico e uso de microrganismo, sementes e mudas, produção animal, qualidade dos alimentos, controle de plantas espontâneas, biofertilizantes e caldas, consórcios agrícolas, controle de pragas e doenças, sensoriamento remoto, práticas orgânicas, invenções e conhecimento tradicional, e outros).

A mais abordada pelos trabalhos foi a "adubação orgânica", que apresentou resultados científicos sobre a utilização de estercos, compostagem, o uso de palhadas na agricultura, a comparação entre adubos orgânicos e químicos, a disponibilidade e ciclagem dos nutrientes, adubação verde, biocarvão entre outros assuntos.

A segunda subcategoria mais citada foi o "sistema de plantio" relatando diversas experiências, como práticas de plantio e formas de manejo para diferentes culturas, sistemas de baixa entrada, rendimentos de produção, comparações entre agricultura orgânica e convencional etc.

A terceira subcategoria mais abordada foi o "controle biológico e uso de microrganismos" apresentando informações sobre inoculação do solo, comunidade de insetos e inimigos naturais, fungos micorrízicos, biocontrole de pragas e doenças (como o uso do Bacillus thuringiensis), benefícios da microbiologia etc.

\section{Organizações de agricultores familiares e agroecologia na região do Sul de Minas} Gerais

Com relação às entrevistas e visitas aos sistemas produtivos dos agricultores, aspectos interessantes puderam ser evidenciados. Quando perguntados sobre como eles nomeiam a sua forma de produzir, 5 agricultores responderam que produzem de forma orgânica, 3 de forma orgânica e biodinâmica, 1 de forma agroecológica e 1 declarou ser uma mistura de permacultura, agricultura natural, agricultura orgânica em conjunto com os princípios da Ana Primavesi (pesquisadora em agroecologia). Este resultado 
demonstra que cerca de $90 \%$ dos entrevistados se identificam com a agricultura orgânica em sua forma de produção, possivelmente por este ser o termo utilizado na legislação brasileira e principalmente devido às certificadoras dos sistemas produtivos ecológicos, em sua maioria, certificarem os produtos como orgânicos. Entre os agricultores 9 são certificados e apenas 1 não é.

Ao perguntar a quanto tempo eles produzem de forma ecológica, 2 lavradores se encaixaram na divisão de até cinco anos, 2 entre cinco e dez anos, e 6 agricultores afirmaram produzir de forma ecológica há mais de dez anos.

Portanto, é possível reparar que boa parte destes produtores possui uma experiência prática de cultivo orgânico, contendo diversas técnicas e conhecimentos sobre o manejo ecológico da terra. Essa experiência tem sido reconhecida, tendo em vista que muitos destes agricultores recebem diversas visitas em suas propriedades, realizando pesquisas, dias de campo entre diversas formas de troca de conhecimento.

Dessa forma estes agricultores atuam como protagonistas da produção do conhecimento agroecológico. Esse procedimento condiz com as propostas educativas preconizadas pela agroecologia, que incentiva a troca de saberes e experiências, realizando a interação entre estudiosos, agricultores, estudantes, pesquisadores e extensionistas, construindo o conhecimento em conjunto (RUAS et al., 2006).

Ao questionar se os agricultores entrevistados recebem assistência técnica atualmente, 5 declararam não receber nenhum tipo de assistência, 2 raramente recebem e apenas 3 recebem com alguma frequência. Portanto, a assistência técnica se mostrou deficiente para $70 \%$ dos agricultores entrevistados, provavelmente devido à falta de abrangência e de conhecimento especifico dos órgãos públicos de extensão para formas agroecológicas de fazer agricultura.

Contudo, é possível se questionar como estes agricultores fazem para ter acesso a novos conhecimentos ou como fazem para resolver os problemas encontrados. Foram citadas quatro formas para o acesso ao conhecimento, entre estas: a leitura de livros e o acesso à internet (80\%), a troca de experiências com outros agricultores (60\%), assistência técnica (30\%) e pedir auxílio ao filho que estuda (10\%). 
Porém, mesmo os agricultores trocando experiências e acessando novos conhecimentos, existem certas dificuldades enfrentadas por eles para realizar a produção ecológica de alimentos. Foram citados dez empecilhos ou pontos de gargalo para a produção: o principal deles foi à mão-de-obra (60\%), seguida da assistência técnica/conhecimento (30\%), tecnologias adaptadas/infraestrutura (20\%), frete de produtos/ transporte/ atravessador (20\%), respeitar as leis da agricultura orgânica (10\%), insumos (10\%), processo de certificação (10\%), descarte de produtos para atender o mercado (10\%), estradas (10\%), sendo que um dos produtores rurais declarou não ter dificuldades para produzir.

\section{Os sistemas produtivos e as técnicas agroecológicas utilizadas}

Ao conhecer as propriedades dos agricultores foi possível identificar diversas técnicas de manejo da terra. No campo, o diálogo se tornou mais enriquecedor, tornando possível a identificação das potencialidades das propriedades e as técnicas utilizadas ou criadas por estes agricultores. As técnicas foram divididas em dez temáticas obtendo os seguintes resultados:

Adubação orgânica: segundo o relato dos 10 agricultores entrevistados, $70 \%$ destes utilizam esterco de animais para adubar as suas lavouras; $60 \%$ fazem uso de adubação verde; $50 \%$ compram ou produzem compostos e bokashi; $40 \%$ utilizam calcário, tortas (de mamona ou leguminosas), entre outros adubos minerais (Kamag, Sílica, Sulfomag e/ou Bórax); e 30\% fazem uso de farinha de osso, fosfato natural, cinzas e outros adubos orgânicos (urina de vaca, farinha de alga e/ou carvão de samambaia).

Biofertilizantes e caldas: a calda bordalesa foi à calda mais citada pelos agricultores, tendo o seu uso em $60 \%$ das propriedades familiares entrevistadas; seguido de distintos biofertilizantes com receitas próprias em cada agroecossistema (40\%); a utilização do óleo de nim é feita por 30\% dos agricultores; e 70\% fazem uso de caldas alternativas as anteriores (Extrato de primavera, chás de urtiga e cavalinha, alho e folha de araucária, extrato de alecrim do campo, entre outras).

Sistemas de plantio: os sistemas de plantio dos agricultores são extremamente harmônicos para cada realidade. Entretanto foi possível analisar que 50\% das famílias 
agricultoras fazem rotação de cultura e $20 \%$ realizam pousio após determinado tempo de cultivo.

Mecanização, tração e trabalho manual: todos os agricultores entrevistados afirmaram usar a enxada como ferramenta para os distintos serviços da propriedade; $80 \%$ destes declararam fazer uso de roçadeiras; quanto ao uso de tratores, $60 \%$ alegaram utilizá-los, alguns mais intensivamente e outros poucas vezes ao ano; 50\% destas famílias utilizam tração animal; e 30\%, microtratores ou tobatas.

Técnicas e insumos biodinâmicos: 40\% dos agricultores que participaram desta pesquisa usam para o manejo das suas lavouras os preparados biodinâmicos; 20\%, o calendário astronômico agrícola, o composto biodinâmico ou a homeopatia; e apenas um agricultor utiliza o flandem.

Consórcios agrícolas: $40 \%$ das famílias entrevistadas utilizam o consórcio de culturas de distintas formas (sistemas agroflorestais, culturas de ciclo longo com de ciclo curto, lavoura com adubação verde, pomar com horta, cultivos em sucessão, consórcios com árvores adubadeiras, entre outras).

Uso de controle biológico e microrganismos: 50\% dos lavradores afirmaram utilizar os microrganismos efetivos (E.M.) em suas lavouras; $40 \%$ utilizam um produto comercial de Bacillus thuringiensis; e 20\% declararam utilizar outros agentes biológicos (ácaros predadores, Bauveria bassiana e/ou Metarizium sp.).

Teoria da trofobiose: $30 \%$ dos camponeses alegaram utilizar o princípio da teoria da trofobiose para manejar o seu agroecossistema.

Invenções e conhecimento tradicional: $40 \%$ dos agricultores familiares entrevistados declaram utilizar semeadoras (de cenoura e beterraba) próprias, construídas com materiais de baixo custo; $20 \%$ afirmaram construir estruturas de bambu para secar feijão ou estufa para a produção de hortaliças. Um agricultor demonstrou realizar o tratamento da água negra através da fossa ecológica de evapotranspiração.

Sementes e mudas: $70 \%$ dos camponeses entrevistados afirmaram utilizar sementes/mudas da roça e compradas; $20 \%$ declararam utilizar apenas sementes/mudas da roça e $10 \%$, apenas compradas. Os agricultores citaram cerca de 27 culturas em que 
as sementes/mudas são produzidas na roça. Entre as sementes/mudas compradas, foram citadas 18 culturas.

\section{Relações entre o conhecimento científico e a prática dos agricultores agroecológicos do Sul de Minas Gerais}

Com as informações concebidas por esta pesquisa, verificou-se que existe uma grande semelhança entre as duas formas de conhecimento quanto as informações relacionadas à categoria de conhecimento técnico produtivo e suas subcategorias (Tabela 2).

Em relação às subcategorias adubação orgânica, biofertilizantes e caldas, sistemas de plantio, consórcios agrícolas, controle biológico e uso de microrganismos, invenções e conhecimento tradicional, sementes e mudas, foram encontradas muitas informações semelhantes entre as duas formas de conhecimento, os agricultores e o meio científico tiveram uma alta relação entre estas subcategorias, demonstrando que a prática e a teoria estão associadas.

Tabela 2 - Relações entre o conhecimento científico e o prático dos agricultores

\begin{tabular}{|c|c|c|}
\hline $\begin{array}{l}\text { Subcategorias do } \\
\text { conhecimento técnico } \\
\text { produtivo }\end{array}$ & $\begin{array}{l}\text { Relação dentro da subcategoria } \\
\text { entre as duas formas de } \\
\text { conhecimento }\end{array}$ & $\begin{array}{l}\text { Relação total entre as duas } \\
\text { formas de conhecimento }\end{array}$ \\
\hline Adubação orgânica & Alta relação & \multirow{10}{*}{ Alta relação $(<70 \%)$} \\
\hline Biofertilizantes e caldas & Alta relação & \\
\hline Sistemas de plantio & Alta relação & \\
\hline $\begin{array}{l}\text { Mecanização, tração e } \\
\text { trabalho manual }\end{array}$ & Baixa relação & \\
\hline $\begin{array}{l}\text { Técnicas e insumos } \\
\text { biodinâmicos }\end{array}$ & Baixa relação & \\
\hline Consórcios agrícolas & Alta relação & \\
\hline $\begin{array}{c}\text { Controle biológico e uso de } \\
\text { microrganismo }\end{array}$ & Alta relação & \\
\hline Teoria da trofobiose & Baixa relação & \\
\hline $\begin{array}{l}\text { Invenções e conhecimento } \\
\text { tradicional }\end{array}$ & Alta relação & \\
\hline Sementes e mudas & Alta relação & \\
\hline
\end{tabular}

Porém, as subcategorias mecanização, tração e trabalho manual, técnicas e insumos biodinâmicos, e a teoria da trofobiose tiveram uma baixa relação entre as duas formas de conhecimento. 
Algumas destas técnicas já são utilizadas no meio rural, porém poucos estudos científicos têm sido realizados nestas temáticas. Representando uma dissociação entre a prática e a teoria.

De acordo com os critérios estabelecidos na metodologia, a soma das relações das subcategorias teve um valor igual a 70\%, correspondendo a uma alta relação entre as duas formas de conhecimento.

Apesar dos conhecimentos obterem uma alta relação, é possível perceber que ações extensionistas e de pesquisa em conjunto com os agricultores ainda são necessárias para o progresso das experiências com agroecologia no Sul de Minas Gerais.

\section{CONCLUSÃO}

Foram identificadas inovações tecnológicas em agroecologia, obtendo-se uma alta relação entre os conhecimentos científicos globais e a prática local dos agricultores agroecológicos do Sul de Minas Gerais.

\section{AGRADECIMENTOS}

Aos agricultores e organizações que foram entrevistados para a confecção deste trabalho de pesquisa, pelos seus ensinamentos e por exercer uma das profissões mais importantes do mundo. À Coordenação de Aperfeiçoamento de Pessoal de Nível Superior (CAPES) pela concessão de bolsa de estudos. Ao Conselho Nacional de Desenvolvimento Científico e Tecnológico (CNPq) pelo financiamento do projeto de pesquisa da categoria de enquadramento: MDA/SAF/CNPq - $\mathrm{N}^{\circ}$ 58/2010, chamada 2.

\section{REFERÊNCIAS}

ALTIERI, M. A.; TOLEDO, V. M. The agroecological revolution in Latin America: rescuing nature, ensuring food sovereignty and empowering peasants. Journal of Peasant Studies, London, v. 38, n. 3, p. 587-612, 2011.

ALTIERI, M. A.; FUNES-MONZOTE, F. R.; PETERSEN, P. Agroecologically efficient agricultural systems for smallholder farmers: contributions to food sovereignty. Agronomy for Sustainable Development, Paris, v. 32, n. 1, p. 1-13, 2012. 
BRITTAIN, J. J.; SACOUMAN, R. J. Agrarian transformation and resistance in the Colombian Countryside. Labour, Capital and Society, Montreal,v. 41, n. 1, p. 5683, 2008.

CÁCERES, D. Non-certified organic agriculture: an opportunity for resource-poor farmers? Outlook on Agriculture, Elmsford, v. 34, n. 3, p. 135-140, 2005.

CAMPBELL, H.; ROSIN, C. After the 'Organic Industrial Complex': an ontological expedition through commercial organic agriculture in New Zealand. Journal of Rural Studies, New York,v. 27, n. 4, p. 350-361, 2011.

CARRUTHERS, D. V. Agroecology in Mexico: linking environmental and indigenous struggles. Society and Natural Resources, Madison, v. 10, n. 3, p. 259-272, 1997.

EMPRESA BRASILEIRA DE PESQUISA AGROPECUÁRIA. Marco referencial em agroecologia. Brasília: Embrapa Informação Tecnológica, 2006. 72 p.

GÓMEZ CRUZ, M.Á.; RINDERMANN, R.S.; RUFINO, J.O.; TOVAR, L. G. Situación y desafíos del sector orgánico de México. Revista Mexicana de Ciencias Agrícolas, México, v. 1, p. 593-608, 2010.

PAULL, J.; HENNIG, B. A world map of organic agriculture. European Journal of Social Sciences, Victoria, v. 24, n. 3, p. 360-369, 2011.

PERFECTO, I.; VANDERMEER, J. Biodiversity conservation in tropical agroecosystems: a new conservation paradigm. Year in Ecology and Conservation Biology, New York, v. 1134, p. 173-200, 2008.

ROSSET, P. M.; ALTIERI, M. A. Agroecology versus input substitution: A fundamental contradiction of sustainable agriculture. Society and Natural Resources, London, v. 10, n. 3, p. 283-295, 1997.

RUAS, E. D.; BRANDÃO, I. M. M; CARVALHO, M. A. T.; SOARES M. H. P.; MATIAS, R. F.; GAVA, R. C.; MESONES, W. G. L. P. Metodologia participativa de extensão rural para o desenvolvimento sustentável - MEXPAR. Belo Horizonte: Emater, 2006. 134 p. 
SANTOS, T. C. S.; PISCOPO, M. R. Gestão de projetos: evolução do conhecimento nos eventos científicos na área de administração e engenharia da produção no Brasil. In: SIMPÓSIO INTERNACIONAL DE GESTÃO DE PROJETOS, 2., e SIMPÓSIO INTERNACIONAL DE INOVAÇÃO E SUSTENTABILIDADE, 1., 2013, São Paulo. Anais... São Paulo: Uninove, 2013. 1 CD ROM.

SCIELO. Disponível em: 〈http://www.scielo.org/php/index.php>. Acesso em: 14 abr. 2014.

SCIVERSE SCOPUS. Disponível em: 〈http://www.scopus.com/>. Acesso em: 30 abr. 2014.

SOUSA, A. A. D.; AZEVEDO, E.; LIMA, E. E.; SILVA, A. P. F. Alimentos orgânicos e saúde humana: estudo sobre as controvérsias. Revista Panamericana de Salud Pública, Washington,v. 31, p. 513-517, 2012.

SOUZA, C. D.; DE FILIPPO, D.; FARIA, . I. L.; CASADO, E. S. Estudo bibliométrico da produção científica do setor citrícola no Brasil: análise de publicações na Web of Science (2000-2010). Liinc em Revista, Rio de Janeiro, v. 9, n. 1, p. 28-46, maio 2013.

VANDERMEER, J.; PERFECTO, I. Complex traditions: intersecting theoretical frameworks in agroecological research. Agroecology and Sustainable Food Systems, London, v. 37, n. 1, p. 76-89, 2013.

WEB OF SCIENCE. Disponível em: <http://wokinfo.com/ >. Acesso em: 30 abr. 2014.

Recebido em: 07 de agosto de 2019. Aceito em: 06 de maio de 2020. 